\title{
Magnetic Liquid Crystals for Molecular Spintronics
}

\author{
J. Szczytko ${ }^{a}, \mathrm{P} . \mathrm{Budzowski}^{a}, \mathrm{H} \cdot \mathrm{Turski}^{a}, \mathrm{~B} \cdot \mathrm{Witek}^{a}$, \\ A. Glebowska ${ }^{b}$, A. KróWCZyński ${ }^{b}$, D. Pociecha ${ }^{b}$, \\ J. Szydlowska ${ }^{b}$, E. GóreckA ${ }^{b}$ AND A. Twardowski ${ }^{a}$ \\ ${ }^{a}$ Institute of Experimental Physics, Faculty of Physics, University of Warsaw \\ Hoża 69, 00-681 Warsaw, Poland \\ ${ }^{b}$ Department of Chemistry, University of Warsaw \\ al. Żwirki i Wigury 101, 02-089 Warsaw, Poland
}

The magnetic properties of $\mathrm{Ni}(\mathrm{II})$ and $\mathrm{Cu}(\mathrm{II})$ complexes were measured. In the case of $\mathrm{Ni}$ (II) samples strong enhancement of the magnetic susceptibility below $23 \mathrm{~K}$ was observed. The model of structural transition was proposed to explain this behavior.

PACS numbers: 75.20.Ck, 75.50.Xx

\section{Introduction}

Growing interest in spintronics and spin control on the atomic level arises from predicted superiority of the spin of the electron over the electron charge in terms of energy and speed efficiency. Advances in this field require a new approach to the concept of spin manipulation [1]. The bottom-up strategy can only be realized by extensive studies of spin interactions in well defined clusters of atoms or molecules. In this communication we present the study of the coupling between paramagnetic cations of copper $\mathrm{Cu}^{2+}$ and nickel $\mathrm{Ni}^{2+}$ incorporated to metal-complex molecules with mesogenic properties [2].

These compounds possess the property of adjustable lattice structure, depending on the type of the compound and the temperature of the system. Still, within the accuracy of measurements, modifications of the external structure of the compounds do not seem to affect in a significant manner the magnetic properties of the complex, which seem to depend solely on the internal structure of the compounds.

\section{Samples and magnetization measurement}

The new nickel(II) complexes of aminomethylene derivatives of barbituric acid [3] and enaminoketone copper(II) [4] has been obtained (Fig. 1). The phase 


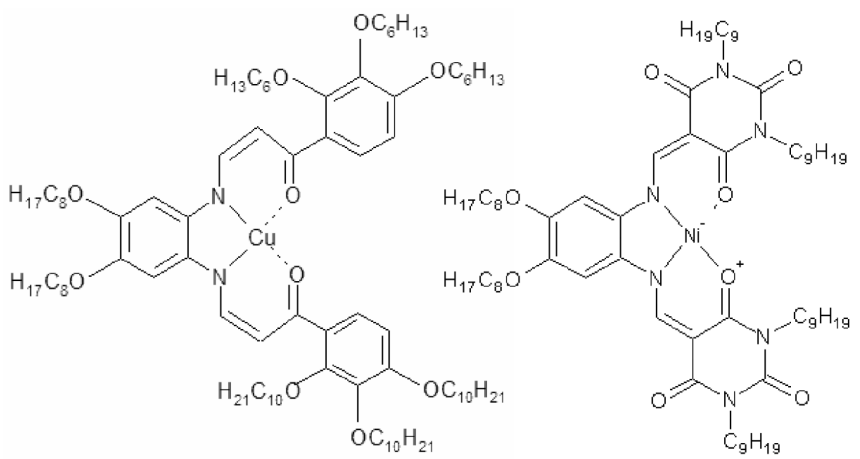

Fig. 1. The example of investigated liquid-crystal complexing compound $\left(\mathrm{Cu}^{2+}, \mathrm{Ni}^{2+}\right)$.

TABLE

General structure of metal complexes studied at liquid crystalline phases, phase transition temperatures $\left(\right.$ in $\left.{ }^{\circ} \mathrm{C}\right)$.

\begin{tabular}{c|c|c|c}
\hline \hline & Cr & Colho $_{\text {ho }}$ & Colhd \\
\hline $\mathrm{Cu}$ & 138.0 & & \\
$\mathrm{Ni}$ & 119.9 & 141.7 & 184.3 \\
\hline
\end{tabular}

Cr - crystal,

Col $_{\text {ho }}$ - columnal hexagonal ordered,

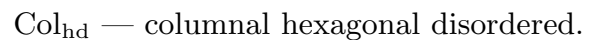

sequence and phase transition temperatures for studied complexes are summarized in Table [3-5]. Due to the discoidal molecular shape this substances form columnar mesophases.

Magnetization measurements were performed using superconducting quantum interference device (SQUID) in the range of magnetic fields 0-6.0 $\mathrm{T}$ and temperatures $2.0-300.0 \mathrm{~K}$.

\section{Results and discussion}

It is expected that the ground state of $\mathrm{Cu}(\mathrm{II})$ ion in tetragonal configuration of the chelating plane is a spin doublet $\left(d^{9}, S=1 / 2\right)$, while the Ni(II) complex should be non-magnetic singlet $\left(d^{8}, S=0\right)$ [6]. Indeed, for the copper(II) complex magnetization demonstrates paramagnetic behavior (Fig. 2a), which can be fitted with the Curie law and $S=1 / 2$. However, magnetic characterization of nickel(II) complex revealed its paramagnetic behavior in a broad temperature range. Below $23 \mathrm{~K}$ the low field magnetization starts to increase rapidly (Fig. 2b). 


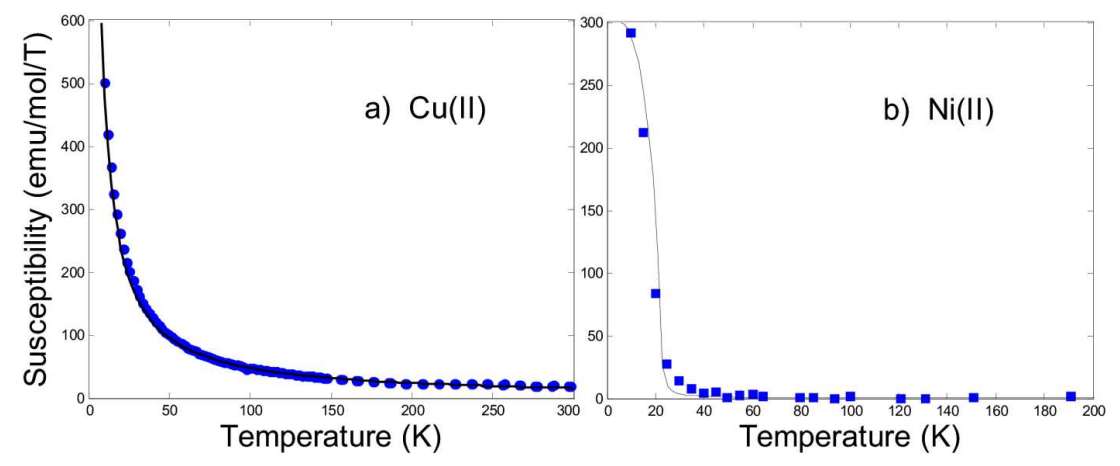

Fig. 2. The magnetization of investigated compound as a function of temperature (a) for the sample with $\mathrm{Cu}$ (II) measured with $1.0 \mathrm{~T}$; (b) for the sample with $\mathrm{Ni}$ (II) measured in $0.10 \mathrm{~T}$. The black curve is the fit to (a) the Curie law, (b) mean field model with $T_{\mathrm{C}}=23 \mathrm{~K}$.

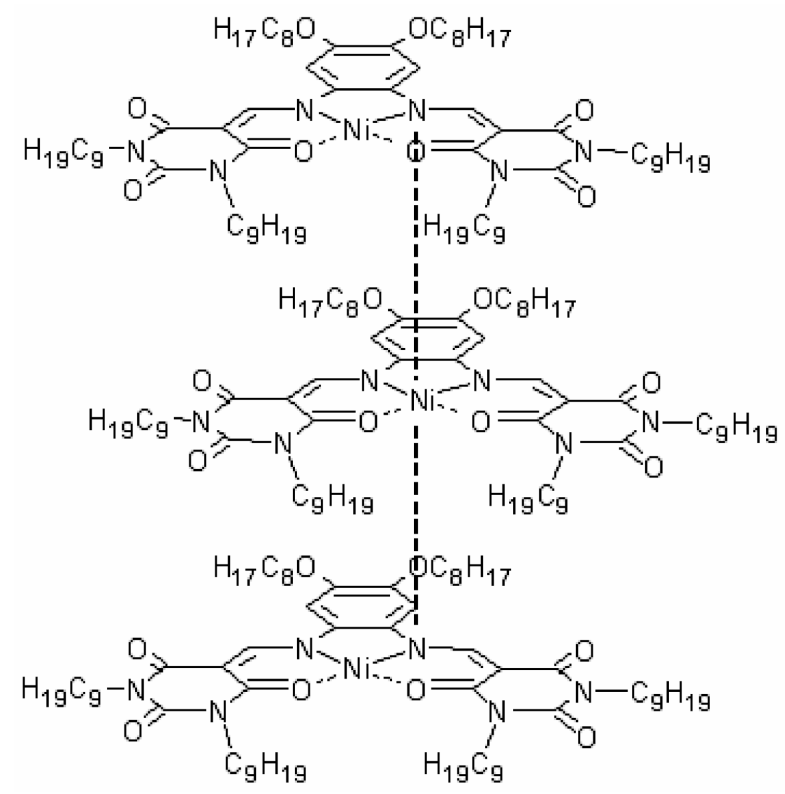

Fig. 3. Chains of magnetic moments in columnar structure of $\mathrm{Ni}(\mathrm{II})$ imposed by chelating of metal center by atoms of neighboring complexes.

Observed paramagnetism of this $\mathrm{Ni}$ (II) complex is most probably of Van Vleck type [6]. The low-temperature ferromagnetism may originate from $\mathrm{Ni}-\mathrm{Ni}$ interactions, resulting in chains of magnetic moments in columnar structure (Fig. 3). Using mean field approximation model for the $\mathrm{Ni}(\mathrm{II})$ ion chains and assuming only nearest neighbors coupling one can estimate $\mathrm{Ni}-\mathrm{Ni}$ exchange interaction to be $J / k_{\mathrm{B}}=+17 \mathrm{~K}$ (for $S=1$ ). However, it is not possible at present to show 
clearly what kind of molecular interactions facilitates paramagnetic-ferromagnetic phase transition. It is possible that the transition is accompanied by the change in the complex geometry from flat to tetrahedral or octahedral, formed in additional chelating by neighboring axial molecules in the column, which affects the $\mathrm{Ni}(\mathrm{II})$ ion ground electronic state (Fig. 3).

\section{Summary}

Summarizing, some of the transition metals complexes seem to be promising materials for pseudo one-dimensional ferromagnets. The ferromagnetic state is observed for $\mathrm{Ni}(\mathrm{II})$ complexes at low temperature. The spin interactions, leading to ferromagnetism most probably are enhanced by bridging the complexes along the columns by chelating centers of neighboring molecules. Low-temperature $\mathrm{X}$-ray diffraction should be performed in order to decide whether the structure change can account for the ferromagnetic transition.

\section{Acknowledgments}

The partial support from European Network of Excellence MTKD-CT-2005029671 is acknowledged.

\section{References}

[1] M. Hanack, Tr. J. Chem. 22, 13 (1998); M. Hanack, M. Lang, Adv. Mater. 6, 819 (1994).

[2] J.L. Serrano, in: Metallomesogens: Synthesis, Properties and Applications, VCH, Weinheim 1996, p. 43; B. Donnio, D. Guillon, R. Deschenaux, D.W. Bruce, in: Comprehensive Coordination Chemistry II, Eds. J.A. McCleverty, J.J. Meyer, M. Fujita, A. Powell, Vol. 7, Elsevier, Oxford 2003, p. 353.

[3] A. Głębowska, K. Kamieńska-Trela, Adam Krówczyński, D. Pociecha, J. Szydłowska, J. Szczytko, A. Twardowski, J. Wójcik, E. Górecka, J. Mater. Chem. 18, 3419 (2008), DOI: 10.1039/b807656a.

[4] A. Krowczynski, J. Szydlowska, D. Pociecha, J. Przedmojski, E. Gorecka, Liq. Cryst. 25, 117 (1998).

[5] U. Pietrasik, J. Szydlowska, A. Krowczynski, D. Pociecha, E. Gorecka, D. Guillon, J. Am. Chem. Soc. 124, 8884 (2002).

[6] C. Kittel, in: Introduction to Solid State Physics, Wiley, 2005; L. Piela, in: Ideas of Quantum Chemistry, Elsevier, 2006. 